\title{
Usulan Perencanaan dan Pengendalian Persediaan Bahan Baku Menggunakan Metode Lot Sizing pada Pabrik Mebel
}

\section{Raw Material's Inventory Planning and Control Using Lot Sizing Method on Furniture Factory}

\author{
Mirna Lusiani ${ }^{1 *}$, Willy Sandi ${ }^{2}$ \\ 1,2Program Studi Teknik Industri, Universitas Bunda Mulia, Jl. Lodan Raya No. 2 Ancol, Jakarta Utara \\ 14430, Indonesia \\ *e-mail: mlusiani@bds.ac.id ${ }^{1}$
}

Received: March 8, 2017; Revised: April 5, 2017; Accepted: April 27, 2017

\begin{abstract}
ABSTRAK
Penelitian ini membahas tentang perencanaan dan pengendalian persediaan bahan baku di PT Rackindo Setara Perkasa yang merupakan salah satu perusahaan manufaktur di Indonesia yang bergerak dalam industri knock-down furniture. Penelitian ini bertujuan untuk melakukan perencanaan dan pengendalian persediaan bahan baku dengan biaya yang terendah. Adapun penelitian yang dilakukan adalah membuat peramalan permintaan tahun 2016, perencanaan agregat menggunakan perangkat lunak LINGO, kemudian dilanjutkan pada perancangan Master Production Schedule (MPS) dan Material Requirement Planning (MRP). Pembuatan MRP dilakukan dengan membandingkan hasil dari beberapa metode Lot Sizing, yaitu Economic Order Quantity (EOQ), Period Order Quantity (POQ) dan Least Total Cost (LTC). Metode Lot Sizing yang dipilih adalah metode yang memberikan biaya persediaan terendah.
\end{abstract}

Kata Kunci: Pengendalian Persediaan, Peramalan, Perencanaan Agregat, Lot Sizing, Master Production Schedule, Material Requirement Planning

\begin{abstract}
This research discusses the planning and inventory control of raw materials in PT Rackindo Setara Perkasa which is one of the manufacturer in Indonesia which is engaged in the industry of knock-down furniture. The purpose of this study is to planning and controlling the inventory of raw materials with the lowest cost. The research is conducted to develop demand forecast in 2016, to develop the aggregate planning using LINGO software, then continued in the design of the Master Production Schedule (MPS) and Material Requirement Planning (MRP). This research discusses the comparison of several methods of Lot Sizing in MRP, such as the Economic Order Quantity (EOQ), Period Order Quantity (POQ) and Least Total Cost (LTC). The selected Lot Sizing method is a method with the lowest inventory cost.
\end{abstract}

Keywords: Inventory Control, Forecasting, Aggregate Planning, Lot Sizing, Master Production Schedule, Material Requirement Planning

\section{PENDAhUluan}

Dewasa kini pasar dan konsumen semakin kritis dengan spesifiasi produk yang ditawarkan. Keadaan ini berakibat pada meningkatnya persaingan antar perusahaan. Untuk menghadapi hal ini maka dibutuhkan peningkatan perusahaan secara internal meliputi peningkatan koordinasi dan pengendalian aktifitas produksi pabrik
(Chinguwa et al., 2013). Hampir setengah dari pengeluaran perusahaan berasal dari biaya persediaan (Lindsey dan Pavur, 2014). Oleh karena itu, manajemen persediaan yang baik akan dapat memberikan manfaat berupa penghematan biaya yang berakibat pada penurunan harga pokok produksi (HPP) serta meningkatnya efisiensi aktifitas produksi. 
PT Rackindo Setara Perkasa merupakan salah satu manufaktur di Indonesia yang bergerak dalam bidang industry knock-down furniture. Pada tahun 2012, perusahaan melakukan re-engineering dan berhasil membuat Produk $\mathrm{C}$ dengan desain yang lebih menarik, proses produksi yang lebih cepat dan harga pokok produksi yang lebih rendah. Permintaan pasar akan Produk C cukup tinggi sehingga pernah mengakibatkan kehabisan persediaan atau stock out.

Dalam upaya untuk mengatasi supaya hal serupa agar tidak terjadi lagi, maka diperlukan suatu perencanaan dan pengedalian persediaan bahan baku. Bahan baku utama yang digunakan dalam memproduksi Produk $\mathrm{C}$ adalah particle board (PB) dan medium density fibreboard (MDF). Berdasarkan hal tersebut, maka penelitian difokuskan pada pengendalian persediaan untuk kedua bahan baku tersebut.

\section{METODOLOGI}

Ada beberapa metode yang dapat digunakan untuk membuat perencanaan dan pengendalian persediaan bahan baku. Secara garis besar, penelitian ini dimulai dengan melakukan peramalan permintaan pada tahun 2016, kemudian hasil peramalan tersebut akan digunakan dalam perencanaan agregat. Selanjutnya dibuatlah MPS berdasarkan hasil perencanaan agregat yang telah didapatkan sebelumnya. Hasil MPS yang didapat akan menjadi variable input dalam penyusunan MRP dengan menggunakan metode lot sizing. Faktor-faktor biaya menjadi pokok perhatian utama dalam penyusunan perencanaan-perencanaan tersebut.
Dalam penelitian ini, untuk mendapatkan hasil peramalan yang memiliki tingkat keakuratan tinggi maka dilakukan pengujian-pengujian tingkat akurasi dari metode-metode peramalan. Pengujian akurasi tersebut dilakukan dengan membandingkan hasil peramalan tahun 2015 dari setiap metode dengan data aktual pada tahun 2015. Metode peramalan yang digunakan dalam penelitian ini meliputi moving average, weighted moving average dan exponential smoothing. Adapun pengujian akurasi tersebut akan menggunakan perhitungan MAPE (mean absolute percentage error), dimana metode yang memberikan nilai MAPE terkecil adalah metode yang dipilih untuk membuat peramalan 2016.

Dalam pembuatan perencanaan agregat dengan LINGO terdapat biaya yang menjadi pertimbangan seperti biaya gaji karyawan, biaya subkontrak, biaya perekrutan karyawan, biaya pemberhentian karyawan, biaya backorder, biaya material. Selain itu faktor lain yang menjadi pertimbangan adalah constraint yang digunakan untuk menyesuaikan formulasi dengan keadaan yang sebenarnya di lapangan. Adapun tujuan dari formulasi yang dibuat adalah untuk mencari nilai biaya terendah.

Berdasarkan hasil perencanaan agregat, maka dibuat perencanaan MPS, dilanjutkan pada pembuatan MRP. Penyusunan MRP akan menggunakan metode Lot Sizing untuk mendapatkan biaya persediaan terendah. Adapun metode lot sizing yang diuji adalah metode Economic Order Quantity (EOQ), Period Order Quantity (POQ) dan Least Total Cost (LTC). 


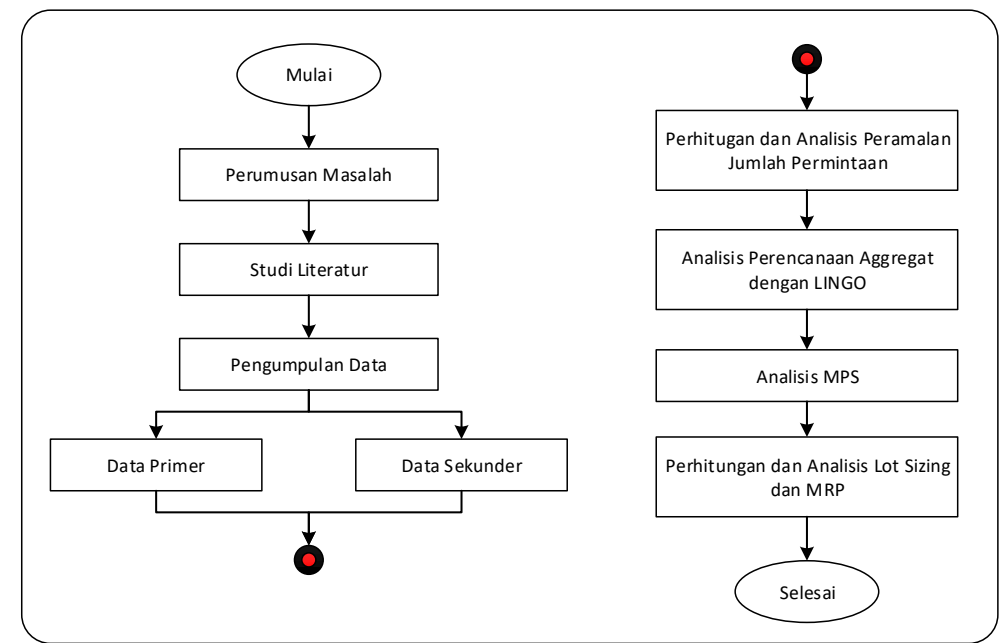

Gambar 1. Diagram Alir Penelitian

\section{HASIL DAN PEMBAHASAN}

Hasil penelitian yang dilakukan sesuai dengan diagram alir yang telah direncanakan sebelumnya dituliskan sesuai dengan urutannya, dimulai dari data yang digunakan dalam penelitian sampai perbandingan metode penerapan lot sizing untuk mendapatkan biaya operasional terendah.

\section{Data}

Berikut adalah data jumlah permintaan Produk C dari tahun 2012-2015.

Tabel 1. Jumlah Permintaan Produk C

\begin{tabular}{|c|l|c|c|c|c|}
\hline \multirow{2}{*}{ No. } & \multirow{2}{*}{ Bulan } & \multicolumn{4}{|c|}{ Tahun } \\
\cline { 3 - 6 } & & $\mathbf{2 0 1 2}$ & $\mathbf{2 0 1 3}$ & $\mathbf{2 0 1 4}$ & $\mathbf{2 0 1 5}$ \\
\hline 1 & Januari & & 1148 & 660 & 542 \\
\hline 2 & Februari & & 1027 & 680 & 462 \\
\hline 3 & Maret & & 1038 & 500 & 457 \\
\hline 4 & April & & 612 & 550 & 279 \\
\hline 5 & Mei & 412 & 868 & 17 & 305 \\
\hline 6 & Juni & 668 & 791 & 732 & 321 \\
\hline 7 & Juli & 418 & 600 & 514 & 321 \\
\hline 8 & Agustus & 965 & 888 & 376 & 445 \\
\hline 9 & September & 1038 & 1056 & 470 & 324 \\
\hline 10 & Oktober & 764 & 555 & 664 & 336 \\
\hline 11 & November & 705 & 527 & 390 & 318 \\
\hline 12 & Desember & 847 & 559 & 408 & 387 \\
\hline \multicolumn{2}{|l|}{ Total } & $\mathbf{5 8 1 7}$ & $\mathbf{9 6 6 9}$ & $\mathbf{5 9 6 1}$ & $\mathbf{4 4 9 7}$ \\
\hline
\end{tabular}

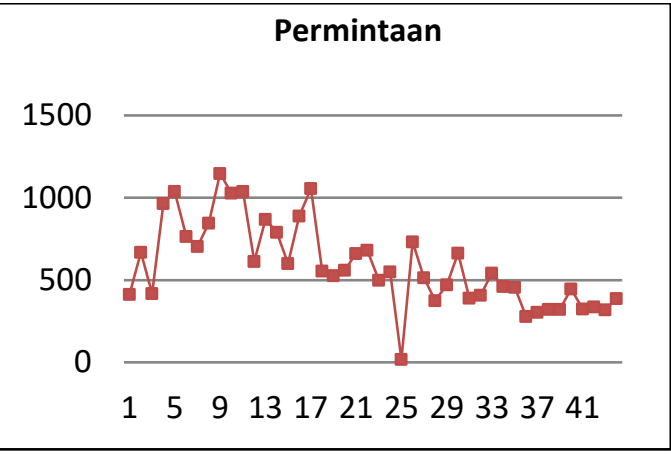

Gambar 2. Grafik Data Jumlah Permintaan

Produk C

\section{Peramalan}

Berdasarkan data yang telah dikumpulkan, maka dilakukan pengujian metode peramalan dengan menghitung nilai MAPE pada tahun 2015. Perhitungan MAPE adalah dengan membandingkan hasil peramalan tahun 2015 dengan jumlah permintaan sebenarnya di tahun 2015. Berikut adalah beberapa metode peramalan yang akan digunakan:

1. Moving Average. Penggunaan metode ini dilakukan sebanyak 4 kali dengan melakukan variasi pada nilai periode dalam setiap perhitungan.

2. Weighted Moving Average. Penggunaan metode ini dilakukan sebanyak 2 kali dengan melakukan variasi pada nilai weight dalam setiap perhitungan.

3. Exponential smoothing. Penggunaan metode ini dilakukan sebanyak 3 kali dengan melakukan variasi pada nilai smoothing index dalam setiap perhitungan. 
Tabel 3 adalah hasil peramalan tahun 2015 dari setiap metode peramalan yang digunakan. Berdasarkan hasil peramalan tahun 2015, maka dilakukan perhitungan MAPE untuk mencari metode yang memberikan peramalan paling akurat. MAPE dari setiap metode peramalan yang dilakukan berkisar antara 10$20 \%$ sehingga berrdasarkan Tabel 2 maka dapat dikatakan peramalan sudah berpotensi baik (akurat). Kemudian berdasarkan hasil pada Tabel 4 didapatkan bahwa metode WMA 2 memberikan hasil peramalan paling akurat dibandingkan dengan metode lainnya. Nilai MAPE dari metode WMA 2 adalah sebesar $15,17 \%$. Berdasarkan hasil ini maka peramalan permintaan untuk tahun 2016 akan menggunakan metode WMA 2.

Tabel 2. Keterangan Variasi Pada Setiap Metode Peramalan

\begin{tabular}{|c|c|c|c|c|c|c|c|}
\hline \multirow{2}{*}{$\begin{array}{l}\text { Metode } \\
\text { Moving } \\
\text { Average }\end{array}$} & \multirow{2}{*}{ Periode } & \multirow{2}{*}{$\begin{array}{c}\text { Metode } \\
\text { Weighted Moving } \\
\text { Average }\end{array}$} & \multicolumn{3}{|c|}{ Weight } & \multirow{2}{*}{$\begin{array}{c}\text { Metode } \\
\text { Exponential } \\
\text { Smoothing }\end{array}$} & \multirow{2}{*}{$\begin{array}{c}\text { Smoothing } \\
\text { index }\end{array}$} \\
\hline & & & 1 & 2 & 3 & & \\
\hline MA 1 & 3 bulan & WMA 1 & 0,6 & 0,3 & 0,1 & Exp 1 & 0,1 \\
\hline MA 2 & 4 bulan & WMA 2 & 0,5 & 0,3 & 0,2 & $\operatorname{Exp} 2$ & 0,2 \\
\hline MA 3 & 5 bulan & & & & & Exp 3 & 0,3 \\
\hline MA 4 & 6 bulan & & & & & & \\
\hline
\end{tabular}

Tabel 3. Hasil Peramalan Tahun 2015

\begin{tabular}{|l|c|c|c|c|c|c|c|c|c|c|}
\hline \multicolumn{1}{|c|}{ Bulan } & MA 1 & MA 2 & MA 3 & MA 4 & WMA 1 & WMA 2 & Exp 1 & Exp 2 & Exp 3 & Actual \\
\hline Januari & 488 & 483 & 462 & 471 & 429 & 454 & 408 & 408 & 408 & 542 \\
\hline Februari & 447 & 501 & 495 & 475 & 487 & 472 & 422 & 435 & 449 & 462 \\
\hline Maret & 471 & 451 & 494 & 490 & 481 & 476 & 426 & 441 & 453 & 457 \\
\hline April & 487 & 468 & 452 & 488 & 467 & 476 & 430 & 445 & 455 & 279 \\
\hline Mei & 400 & 435 & 430 & 423 & 351 & 369 & 415 & 412 & 403 & 305 \\
\hline Juni & 347 & 376 & 409 & 409 & 313 & 328 & 404 & 391 & 374 & 321 \\
\hline Juli & 302 & 341 & 365 & 395 & 312 & 308 & 396 & 377 & 359 & 321 \\
\hline Agustus & 316 & 307 & 337 & 358 & 320 & 318 & 389 & 366 & 348 & 445 \\
\hline September & 363 & 348 & 335 & 355 & 396 & 383 & 395 & 382 & 378 & 324 \\
\hline Oktober & 364 & 353 & 344 & 333 & 360 & 360 & 388 & 371 & 362 & 336 \\
\hline November & 369 & 357 & 350 & 342 & 344 & 355 & 383 & 364 & 355 & 318 \\
\hline Desember & 326 & 356 & 349 & 345 & 324 & 325 & 377 & 355 & 344 & 387 \\
\hline Total & 4680 & 4776 & 4822 & 4884 & 4584 & 4624 & 4833 & 4747 & 4688 & 4497 \\
\hline
\end{tabular}

Tabel 4. Nilai MAPE Setiap Metode Peramalan Tahun 2015

\begin{tabular}{|c|c|c|c|c|c|c|c|c|c|}
\hline Metode & WMA 2 & WMA 1 & MA 2 & MA 4 & MA 1 & MA 3 & Exp 3 & $\operatorname{Exp~2~}$ & Exp 1 \\
\hline MAPE & $15,17 \%$ & $15,51 \%$ & $15,70 \%$ & $15,72 \%$ & $15,79 \%$ & $15,84 \%$ & $16,39 \%$ & $17,21 \%$ & $18,01 \%$ \\
\hline
\end{tabular}

Tabel 5. Hasil Peramalan Permintaan Tahun 2016

\begin{tabular}{lclc}
\hline \multicolumn{1}{c}{ Bulan } & Peramalan 2016 & \multicolumn{1}{c}{ Bulan } & Peramalan 2016 \\
\hline Januari & 357 & Juli & 363 \\
Februari & 359 & Agustus & 363 \\
Maret & 364 & September & 363 \\
April & 362 & Oktober & 363 \\
Mei & 362 & November & 363 \\
Juni & 363 & Desember & 363 \\
\hline
\end{tabular}




\section{Perencanaan Agregat}

Penyusunan perencanaan agregat akan menggunakan bantuan software LINGO.14 untuk mendapatkan hasil yang optimal. Persamaan (1) adalah formulasi total biaya yang akan dicari nilai minimumnya:

$T C=R T+O T+H+L+I+S+P+C$

Tabel 6. Keterangan Rumusan Total Biaya

\begin{tabular}{|c|c|c|}
\hline $\begin{array}{c}\text { Bia } \\
\text { ya }\end{array}$ & Keterangan & Rumusan \\
\hline$R T$ & $\begin{array}{l}\text { Regular time } \\
\text { cost }\end{array}$ & $\begin{array}{l}W_{t} \mathrm{X} \text { biaya regular } \\
\text { worker }\end{array}$ \\
\hline$O T$ & Overtime cost & $O_{t} \mathrm{X}$ biaya overtime \\
\hline$H$ & Hirring cost & $H_{t} \mathrm{X}$ bia \\
\hline$L$ & Layoff cost & $L_{t} \mathrm{X}$ biaya layoff \\
\hline I & Invento & $\begin{array}{l}I_{t} \mathrm{X} \text { biaya inventory } \\
\text { carrying cost }\end{array}$ \\
\hline$S$ & $\begin{array}{l}\text { Stockout / } \\
\text { backorder cost }\end{array}$ & $S_{t} \mathrm{X}$ biaya backorder \\
\hline$P$ & $\begin{array}{l}\text { Unit production } \\
\text { cost }\end{array}$ & $P_{t} \mathrm{X}$ biaya material \\
\hline$C$ & $\begin{array}{l}\text { Subcontract } \\
\text { cost }\end{array}$ & $\begin{array}{l}C_{t} \mathrm{X} \text { biaya } \\
\text { subcontract }\end{array}$ \\
\hline
\end{tabular}

Keterangan variable:

$W_{t} \quad=$ jumlah regular worker pada periode $t$

$O_{t} \quad=$ jumlah overtime pada periode $t$

$H_{t} \quad=$ jumlah hirring pada periode $t$

$L_{t} \quad=$ jumlah layoff pada periode $t$

$I_{t} \quad=$ jumlah inventory pada periode $t$

$S_{t} \quad=$ jumlah backorder pada periode $t$

$P_{t} \quad=$ jumlah material yang digunakan pada periode $t$

$C_{t} \quad=$ jumlah subcontract pada periode $t$

Tabel 7. Keterangan biaya Perencanaan Agregat

\begin{tabular}{|l|lr|l|}
\hline \multicolumn{1}{|c|}{ Keterangan } & \multicolumn{2}{|c|}{ Biaya } & \\
\hline Regular Worker & $\operatorname{Rp} 3.100 .000,00$ & /bulan \\
\hline Overtime & $\operatorname{Rp}$ & $749.136,00$ & /overtime \\
\hline Hiring & $\operatorname{Rp}$ & $495.000,00$ & /orang \\
\hline Layoff & $\operatorname{Rp}$ & $270.000,00$ & /orang \\
\hline Subcontract & $\mathrm{Rp}$ & $278.831,00$ & /unit \\
\hline Backorder & $\mathrm{Rp}$ & $421.250,00$ & /unit \\
\hline Inventory Carrying Cost & $\mathrm{Rp}$ & $23.236,00$ & /unit \\
\hline Material & $\mathrm{Rp}$ & $232.359,00$ & /unit \\
\hline
\end{tabular}

\section{Constraint:}

1. Capacity constraint. Kapasitas produksi setiap bulannya sesuai dengan jumlah pekerja yang digunakan. Setiap pekerja melakukan overtime dapat memproduksi 22 unit tambahan.

$P_{t} \leq P C_{t}^{*} W_{t}+22^{*} O_{t}$

Angka 22 pada overtime diperoleh dari waktu produksi untuk satu unit dikalikan lama waktu overtime.

2. Overtime Limit. Batasan jumlah overtime yang dapat dilakukan. Untuk melakukan 1x overtime dibutuhkan 1 pekerja bekerja lebih lama selama 3 jam per hari dalam 1 minggu (6 hari kerja, senin-sabtu dengan 1 shift kerja).

$W_{t} \leq 4 * O_{t}$

3. Workforce hiring and layoff constraint. Berhubungan dengan jumlah pekerja yang digunakan dalam setiap periode berdasarkan penambahan dan pengurangan jumlah pekerja.

$W_{t}=W_{t-1}+H_{t}-L_{t}$

4. Inventory constraint. Jumlah inventory dan kaitannya dengan subcontract, backorder, producted unit.

$P_{t}+C_{t}+I_{t-1}=$ Demand $+S_{t^{-1}}+I_{t}+S_{t}$

Tabel 9 menunjukkan hasil perencanaan agregat yang didapatkan setelah menjalankan software LINGO 14.0. Hasil tersebut bersifat global optimal, sehingga dapat dikatakan hasil tersebut adalah hasil yang paling optimal. Selain itu, tidak terdapat infeasibilities sehingga semua constraint tidak ada dilanggar. Berdasarkan hasil perencanaan agregat tersebut, total biaya yang dikeluarkan sebesar $\mathrm{Rp}$ 747.116.674,00. Perencanaan agregat yang diterapkan adalah mengikuti strategi chase without subcontract and backlog, yaitu menyesuaikan jumlah produksi sesuai jumlah permintaaan yang diterima tanpa menggunakan subkontrak dan backlog. 
ISSN 1979-1720 (print) ISSN 2579-8154 (online)
JIEMS

Journal of Industrial Engineering and Management Systems

Vol. 10, No. 2, August 2017

Tabel 8. Matrix Formulasi LINGO

\begin{tabular}{|l|c|c|c|c|c|c|c|c|c|c|c|c|}
\hline Bulan & Januari & Februari & Maret & April & Mei & Juni & Juli & Agustus & 3eptembe & Oktober Novembebesember \\
\hline Day & 22 & 23 & 25 & 23,5 & 24 & 24 & 0 & 24 & 23 & 23,5 & 24 & 24,5 \\
\hline $\mathbf{D}_{\mathbf{t}}$ & 357 & 359 & 364 & 362 & 362 & 363 & 363 & 363 & 363 & 363 & 363 & 363 \\
\hline $\mathbf{P C}_{\mathbf{t}}$ & 222 & 232 & 252 & 237 & 242 & 242 & 0 & 242 & 232 & 237 & 242 & 247 \\
\hline $\mathbf{W}_{\mathbf{t}}$ & $\mathrm{x} 1$ & $\mathrm{x} 9$ & $\mathrm{x} 17$ & $\mathrm{x} 25$ & $\mathrm{x} 33$ & $\mathrm{x} 41$ & $\mathrm{x} 49$ & $\mathrm{x} 57$ & $\mathrm{x} 65$ & $\mathrm{x} 73$ & $\mathrm{x} 81$ & $\mathrm{x} 89$ \\
\hline $\mathbf{O}_{\mathbf{t}}$ & $\mathrm{x} 2$ & $\mathrm{x} 10$ & $\mathrm{x} 18$ & $\mathrm{x} 26$ & $\mathrm{x} 34$ & $\mathrm{x} 42$ & $\mathrm{x} 50$ & $\mathrm{x} 58$ & $\mathrm{x} 66$ & $\mathrm{x} 74$ & $\mathrm{x} 82$ & $\mathrm{x} 90$ \\
\hline $\mathbf{H}_{\mathbf{t}}$ & $\mathrm{x} 3$ & $\mathrm{x} 11$ & $\mathrm{x} 19$ & $\mathrm{x} 27$ & $\mathrm{x} 35$ & $\mathrm{x} 43$ & $\mathrm{x} 51$ & $\mathrm{x} 59$ & $\mathrm{x} 67$ & $\mathrm{x} 75$ & $\mathrm{x} 83$ & $\mathrm{x} 91$ \\
\hline $\mathbf{L}_{\mathbf{t}}$ & $\mathrm{x} 4$ & $\mathrm{x} 12$ & $\mathrm{x} 20$ & $\mathrm{x} 28$ & $\mathrm{x} 36$ & $\mathrm{x} 44$ & $\mathrm{x} 52$ & $\mathrm{x} 60$ & $\mathrm{x} 68$ & $\mathrm{x} 76$ & $\mathrm{x} 84$ & $\mathrm{x} 92$ \\
\hline $\mathbf{I}_{\mathbf{t}}$ & $\mathrm{x} 5$ & $\mathrm{x} 13$ & $\mathrm{x} 21$ & $\mathrm{x} 29$ & $\mathrm{x} 37$ & $\mathrm{x} 45$ & $\mathrm{x} 53$ & $\mathrm{x} 61$ & $\mathrm{x} 69$ & $\mathrm{x} 77$ & $\mathrm{x} 85$ & $\mathrm{x} 93$ \\
\hline $\mathbf{S}_{\mathbf{t}}$ & $\mathrm{x} 6$ & $\mathrm{x} 14$ & $\mathrm{x} 22$ & $\mathrm{x} 30$ & $\mathrm{x} 38$ & $\mathrm{x} 46$ & $\mathrm{x} 54$ & $\mathrm{x} 62$ & $\mathrm{x} 70$ & $\mathrm{x} 78$ & $\mathrm{x} 86$ & $\mathrm{x} 94$ \\
\hline $\mathbf{P}_{\mathbf{t}}$ & $\mathrm{x} 7$ & $\mathrm{x} 15$ & $\mathrm{x} 23$ & $\mathrm{x} 31$ & $\mathrm{x} 39$ & $\mathrm{x} 47$ & $\mathrm{x} 55$ & $\mathrm{x} 63$ & $\mathrm{x} 71$ & $\mathrm{x} 79$ & $\mathrm{x} 87$ & $\mathrm{x} 95$ \\
\hline $\mathbf{C}_{\mathbf{t}}$ & $\mathrm{x} 8$ & $\mathrm{x} 16$ & $\mathrm{x} 24$ & $\mathrm{x} 32$ & $\mathrm{x} 40$ & $\mathrm{x} 48$ & $\mathrm{x} 56$ & $\mathrm{x} 64$ & $\mathrm{x} 72$ & $\mathrm{x} 80$ & $\mathrm{x} 88$ & $\mathrm{x} 96$ \\
\hline
\end{tabular}

\section{Formulasi LINGO}

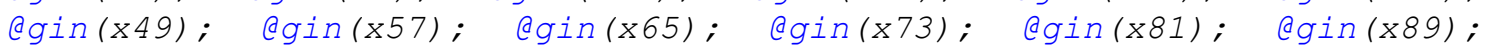

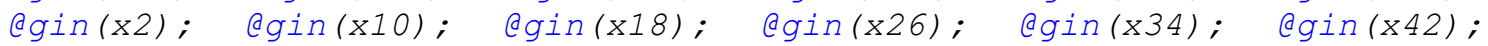
agin(x50); agin(x58); agin(x66); agin(x74); agin(x82); agin(x90);

$\operatorname{Min}=3100000 * x 1+749136 * x 2+495000 * x 3+270000 * x 4+23236 * x 5+421250 * x 6+232359$ $*_{x} 7+278831 * x 8+3100000 * x 9+749136 * x 10+495000 * x 11+270000 * x 12+23236 * x 13+42$ $1250 * x 14+232359 * \times 15+278831 * \times 16+3100000 * x 17+749136 * \times 18+495000 * x 19+27000$ $0 * x 20+23236 * x 21+421250 * x 22+232359 * x 23+278831 * x 24+3100000 * x 25+749136 * x 2$ $6+495000 * x 27+270000 * x 28+23236 * x 29+421250 * x 30+232359 * x 31+278831 * x 32+310$ $0000 * x 33+749136 * x 34+495000 * x 35+270000 * x 36+23236 * x 37+421250 * x 38+232359 *$ $\times 39+278831 * x 40+3100000 * x 41+749136 * x 42+495000 * x 43+270000 * x 44+23236 * x 45+$ $421250 * x 46+232359 * x 47+278831 * x 48+495000 * x 51+270000 * x 52+23236 * x 53+42125$ $0 * x 54+232359 * x 55+278831 * x 56+3100000 * x 57+749136 * x 58+495000 * x 59+270000 * x$ $60+23236 * x 61+421250 * \times 62+232359 * \times 63+278831 * x 64+3100000 * x 65+749136 * \times 66+4$ $95000 * x 67+270000 * x 68+23236 * x 69+421250 * x 70+232359 * x 71+278831 * x 72+310000$ $0 * x 73+749136 * x 74+495000 * x 75+270000 * x 76+23236 * x 77+421250 * x 78+232359 * x 79$ $+278831 * x 80+3100000 * x 81+749136 * x 82+495000 * x 83+270000 * x 84+23236 * x 85+421$ $250 * \times 86+232359 * \times 87+278831 * \times 88+3100000 * \times 89+749136 * \times 90+495000 * \times 91+270000$ ${ }^{*} \times 92+23236 * x 93+421250 * x 94+232359 * \times 95+278831 * x 96$;

$-x 7+222 * x 1+19 * x 2>=0 ; \quad-x 2+4 * x 1>=0 ; \quad-x 1+x 3-x 4=0 ; \quad 357+x 5+x 6-1667-x 7-x 8=0 ;$ $-x 15+232 * x 9+19 * x 10>=0 ; \quad-x 10+4 * x 9>=0 ; \quad-x 9+x 1+x 11-x 12=0 ; \quad 359+x 6+x 13+x 14-$ $x 5-x 15-x 16=0 ;-x 23+252 * x 17+19 * x 18>=0 ;-x 18+4 * x 17>=0 ; \quad-x 17+x 9+x 19-x 20=0 ;$ $364+x 14+x 21+x 22-x 13-x 23-x 24=0 ;-x 31+237 * x 25+19 * x 26>=0 ; \quad-x 26+4 * x 25>=0 ;$ $-x 25+x 17+x 27-x 28=0$; $\times 39+242 * \times 33+19 * \times 34>=0$ $362+\times 22+x 29+x 30-x 21-x 31-x 32=0$ $362+\times 30+x 37+x 38-x 29-x 39-\times 40=0 ;-x 47+242 * x 41+19 * x 42>=0 ;-x 42+4 * x 41>=0 ;-$ $x 41+x 33+x 43-x 44=0 ; \quad 363+x 38+x 45+x 46-x 37-x 47-x 48=0 ; \quad-x 55+0 * x 49+0 * x 50>=0 ;$ $-x 50+4{ }^{*} \times 49>=0 ; \quad-x 49+x 41=0 ; \quad 363+x 46+x 53+x 54-x 45-x 55-x 56=0 ; \quad$ $\times 63+242 * x 57+19 * x 58>=0 ; \quad-x 58+4 * x 57>=0 ; \quad-x 57+x 49+x 59-x 60=0 ;$ $363+x 54+x 61+x 62-x 53-x 63-x 64=0 ;-x 71+232 * x 65+19 * x 66>=0 ;-x 66+4 * x 65>=0 ;-$ $x 65+x 57+x 67-x 68=0$ $\times 79+237 * x 73+19 * x 74>=0$ $363+x 62+x 69+x 70-x 61-x 71-x 72=0 ;$ $\times 81+x 73+x 83-x 84=0$

$\times 95+247 * \times 89+19 * \times 90>=0$; $-x 74+4 * x 73>=0$

$-x 73+x 65+x 75-x 76=0$

$363+x 86+x 93+x 94-x 85-x 95-x 96=0 . \quad-x 90+4 * x 89>=0 ;$ $363+x 78+x 85+x 86-x 77-x 87-x 88=0$; $-x 89+x 81+x 91-x 92=0$ 
Tabel 9. Hasil Formulasi LINGO

\begin{tabular}{|l|c|c|c|c|c|c|c|c|c|c|c|c|}
\hline Bulan & Januari & Februari & Maret & April & Mei & Juni & Juli & \multicolumn{2}{|c|}{ Agustus } & eptembe & Oktober & Novembe Desember \\
\hline Day & 22 & 23 & 25 & 23,5 & 24 & 24 & 0 & 24 & 23 & 23,5 & 24 & 24,5 \\
\hline $\mathbf{D}_{\mathbf{t}}$ & 357 & 359 & 364 & 362 & 362 & 363 & 363 & 363 & 363 & 363 & 363 & 363 \\
\hline $\mathbf{P C}_{\mathbf{t}}$ & 222 & 232 & 252 & 237 & 242 & 242 & 0 & 242 & 232 & 237 & 242 & 247 \\
\hline $\mathbf{W}_{\mathbf{t}}$ & 0 & 0 & 0 & 0 & $\mathbf{1}$ & $\mathbf{3}$ & $\mathbf{3}$ & $\mathbf{2}$ & $\mathbf{2}$ & $\mathbf{2}$ & $\mathbf{2}$ & $\mathbf{1}$ \\
\hline $\mathbf{O}_{\mathbf{t}}$ & 0 & 0 & 0 & 0 & 0 & 0 & 0 & 0 & 0 & 0 & 0 & 0 \\
\hline $\mathbf{H}_{\mathbf{t}}$ & 0 & 0 & 0 & 0 & $\mathbf{1}$ & $\mathbf{2}$ & 0 & 0 & 0 & 0 & 0 & 0 \\
\hline $\mathbf{L}_{\mathbf{t}}$ & 0 & 0 & 0 & 0 & 0 & 0 & 0 & $\mathbf{1}$ & 0 & 0 & 0 & $\mathbf{1}$ \\
\hline $\mathbf{I}_{\mathbf{t}}$ & $\mathbf{1 3 1 0}$ & $\mathbf{9 5 1}$ & $\mathbf{5 8 7}$ & $\mathbf{2 2 5}$ & 0 & $\mathbf{3 6 3}$ & 0 & 0 & 0 & 0 & $\mathbf{1 1 6}$ & 0 \\
\hline $\mathbf{S}_{\mathbf{t}}$ & 0 & 0 & 0 & 0 & 0 & 0 & 0 & 0 & 0 & 0 & 0 & 0 \\
\hline $\mathbf{P}_{\mathbf{t}}$ & 0 & 0 & 0 & 0 & $\mathbf{1 3 7}$ & $\mathbf{7 2 6}$ & 0 & $\mathbf{3 6 3}$ & $\mathbf{3 6 3}$ & $\mathbf{3 6 3}$ & $\mathbf{4 7 9}$ & $\mathbf{2 4 7}$ \\
\hline $\mathbf{C}_{\mathbf{t}}$ & 0 & 0 & 0 & 0 & 0 & 0 & 0 & 0 & 0 & 0 & 0 & 0 \\
\hline
\end{tabular}

\section{Master Production Scheduling (MPS)}

Berdasarkan perencanaan agregat yang telah dibuat, maka dibuatlah MPS produk C tahun 2016 ditampilkan pada Tabel 10. Jumlah lot size berdasarkan kebijakan dari perusahaan adalah 108 unit dan jumlah safety stock yang digunakan adalah minimal 50\% dari jumlah permintaan di periode selanjutnya. Hal ini didasari oleh lead time produksi yang hanya 2 minggu atau 0,5 bulan. Jumlah persediaan yang terdapat di gudang pada periode awal (Januari) adalah sebesar 1667 unit.

\section{Material Requirement Planning (MRP)}

Penyusunan MRP yang dilakukan dalam penelitian ini hanya akan difokuskan pada bahan baku utama dari Produk C, yaitu particle board (PB) dan medium density fibreboard (MDF). Jumlah persediaan awal untuk setiap bahan baku diasumsikan 0 (nol). Tabel 11 adalah data dan asumsi yang digunakan dalam penyusunan MRP:

Dalam perencanaan MRP, jumlah unit yang akan dipesan dan waktu pemesanan akan ditentukan menggunakan metode lot sizing. Terdapat 3 (tiga) metode lot sizing yang digunakan, yaitu: Economic Order Quantity (EOQ), Period Order Quantity (POQ) dan Least Total Cost (LTC).

\section{Economic Order Quantity (EOQ)}

Metode EOQ mengasumsikan jumlah permintaan pada setiap periodenya adalah tetap. Berdasarkan tabel MPS yang telah didapatkan sebelumnya, terlihat bahwa jumlah permintaan pada bulan 1-4 adalah nol. Untuk menghindari kesalahan perhitungan, maka rata-rata permintaan dan biaya penyimpanan dalam setahun yang digunakan dalam perhitungan hanya menggunakan bulan ke 5-12 (8 bulan). Sehingga rata-rata permintaan untuk $\mathrm{PB}$ adalah 462 unit/bulan dan rata-rata permintaan MDF adalah 141 unit/bulan. Holding cost yang digunakan adalah sebesar $6,67 \%$.

Tabel 12 dan Tabel 13 menampilkan hasil perhitungan hasil MRP dengan menggunakan EOQ. Bahan baku PB ditampilkan pada Tabel 12 dengan nilai hasil perhitungan EOQ sebesar 847 unit, sedangkan bahan baku MDF ditampilkan pada Tabel 13 dengan nilai hasil perhitungan EOQ sebesar 574 unit.

Tabel 10. Master Production Scheduling (MPS) 2016

\begin{tabular}{lcccccccccccc}
\hline Keterangan & Jan & Feb & Mar & Apr & May & Jun & Jul & Aug & Sep & Oct & Nov & Dec \\
\hline F & 357 & 359 & 364 & 362 & 362 & 363 & 363 & 363 & 363 & 363 & 363 & 363 \\
CO & 397 & 362 & 308 & 207 & & & & & & & & \\
POH & 1667 & 1270 & 908 & 544 & 182 & 252 & 645 & 282 & 243 & 204 & 273 & 234 \\
MPS & 0 & 0 & 0 & 0 & 432 & 756 & 0 & 324 & 324 & 432 & 324 & 216 \\
ATP & 1270 & 908 & 544 & 182 & 252 & 645 & 282 & 243 & 204 & 273 & 234 & 87 \\
\hline
\end{tabular}


Tabel 11. Keterangan untuk Bahan Baku PB dan MDF

\begin{tabular}{lcc}
\hline \multicolumn{1}{c}{ Keterangan } & PB & MDF \\
\hline Jumlah yang Dibutuhkan per Unit Produksi Produk C & $112 / 100$ unit & $34 / 100$ unit \\
Lead Time & 2 bulan & 2 bulan \\
Biaya Pemesanan (Ordering Cost) (Rp) & $6,540,250.0$ & $6,540,250.0$ \\
Harga Bahan Baku (Rp) & $126,375.0$ & $84,250.0$ \\
Biaya Persediaan (Holding Cost) (Rp) & $12,637.5$ & $8,425.0$ \\
\hline
\end{tabular}

Tabel 12. Hasil MRP Bahan Baku PB Menggunakan EOQ

\begin{tabular}{|l|c|c|c|c|c|c|c|c|c|c|c|c|}
\hline Bulan & $\mathbf{1}$ & $\mathbf{2}$ & $\mathbf{3}$ & $\mathbf{4}$ & $\mathbf{5}$ & $\mathbf{6}$ & $\mathbf{7}$ & $\mathbf{8}$ & $\mathbf{9}$ & $\mathbf{1 0}$ & $\mathbf{1 1}$ & $\mathbf{1 2}$ \\
\hline Gross Requirements & 0 & 0 & 0 & 0 & 560 & 896 & 0 & 448 & 448 & 560 & 448 & 336 \\
\hline Scheduled Receipts & & & & & & & & & & & & \\
\hline Projected On Hand & 0 & 0 & 0 & 0 & 0 & 287 & 238 & 238 & 637 & 189 & 476 & 28 \\
\hline Net Requirement & 0 & 0 & 0 & 0 & 560 & 609 & 0 & 210 & 0 & 371 & 0 & 308 \\
\hline Planned Order Receipts & & & & & 847 & 847 & & 847 & & 847 & & 847 \\
\hline Planned Order Release & 0 & 0 & 847 & 847 & 0 & 847 & 0 & 847 & 0 & 847 & 0 & 0 \\
\hline
\end{tabular}

Tabel 13. Hasil MRP Bahan Baku MDF Menggunakan EOQ

\begin{tabular}{|l|c|c|c|c|c|c|c|c|c|c|c|c|}
\hline Bulan & $\mathbf{1}$ & $\mathbf{2}$ & $\mathbf{3}$ & $\mathbf{4}$ & $\mathbf{5}$ & $\mathbf{6}$ & $\mathbf{7}$ & $\mathbf{8}$ & $\mathbf{9}$ & $\mathbf{1 0}$ & $\mathbf{1 1}$ & $\mathbf{1 2}$ \\
\hline Gross Requirements & 0 & 0 & 0 & 0 & 170 & 272 & 0 & 136 & 136 & 170 & 136 & 102 \\
\hline Scheduled Receipts & & & & & & & & & & & & \\
\hline Projected On Hand & 0 & 0 & 0 & 0 & 0 & 404 & 132 & 132 & 570 & 434 & 264 & 128 \\
\hline Net Requirement & 0 & 0 & 0 & 0 & 170 & 0 & 0 & 4 & 0 & 0 & 0 & 0 \\
\hline Planned Order Receipts & & & & & 574 & & & 574 & & & & \\
\hline Planned Order Release & 0 & 0 & 574 & 0 & 0 & 574 & 0 & 0 & 0 & 0 & 0 & 0 \\
\hline
\end{tabular}

Tabel 14. Hasil MRP Bahan Baku PB Menggunakan POQ

\begin{tabular}{|l|c|c|c|c|c|c|c|c|c|c|c|c|}
\hline Bulan & $\mathbf{1}$ & $\mathbf{2}$ & $\mathbf{3}$ & $\mathbf{4}$ & $\mathbf{5}$ & $\mathbf{6}$ & $\mathbf{7}$ & $\mathbf{8}$ & $\mathbf{9}$ & $\mathbf{1 0}$ & $\mathbf{1 1}$ & $\mathbf{1 2}$ \\
\hline Gross Requirements & 0 & 0 & 0 & 0 & 560 & 896 & 0 & 448 & 448 & 560 & 448 & 336 \\
\hline Scheduled Receipts & & & & & & & & & & & & \\
\hline Projected On Hand & 0 & 0 & 0 & 0 & 0 & 896 & 0 & 448 & 0 & 560 & 0 & 336 \\
\hline Net Requirement & 0 & 0 & 0 & 0 & 560 & 0 & 0 & 0 & 448 & 0 & 448 & 0 \\
\hline Planned Order Receipts & & & & & 1456 & & 448 & & 1008 & & 784 & \\
\hline Planned Order Release & & & 1456 & & 448 & & 1008 & & 784 & & & \\
\hline
\end{tabular}

Tabel 15. Hasil MRP Bahan Baku MDF Menggunakan POQ

\begin{tabular}{|l|c|c|c|c|c|c|c|c|c|c|c|c|}
\hline Bulan & $\mathbf{1}$ & $\mathbf{2}$ & $\mathbf{3}$ & $\mathbf{4}$ & $\mathbf{5}$ & $\mathbf{6}$ & $\mathbf{7}$ & $\mathbf{8}$ & $\mathbf{9}$ & $\mathbf{1 0}$ & $\mathbf{1 1}$ & $\mathbf{1 2}$ \\
\hline Gross Requirements & 0 & 0 & 0 & 0 & 170 & 272 & 0 & 136 & 136 & 170 & 136 & 102 \\
\hline Scheduled Receipts & & & & & & & & & & & & \\
\hline Projected On Hand & 0 & 0 & 0 & 0 & 0 & 408 & 136 & 136 & 0 & 408 & 238 & 102 \\
\hline Net Requirement & 0 & 0 & 0 & 0 & 170 & 0 & 0 & 0 & 136 & 0 & 0 & 0 \\
\hline Planned Order Receipts & & & & & 578 & & & & 544 & & & \\
\hline Planned Order Release & & & 578 & & & & 544 & & & & & \\
\hline
\end{tabular}

\section{Period Order Quantity (POQ)}

Berdasarkan hasil perhitungan untuk bahan baku PB, didapatkan nilai POQ sebesar 1,833 bulan $\approx 2$ bulan. Tabel 14 menunjukkan hasil MRP bahan baku PB. Tabel 15 menjelaskan hasil MRP bahan baku MDF dengan menggunakan metode POQ. Nilai POQ untuk bahan baku MDF adalah sebesar 4,064 bulan $\approx 5$ bulan.

\section{Least Total Cost (LTC)}

Tabel 16 dan Tabel 17 menjelaskan perhitungan dengan menggunakan metode LTC masing-masing untuk bahan baku PB dan MDF. Rumus yang digunakan sebagai dasar perhitungan ditampilkan pada persamaan (6) hingga persamaan (9).

$C O Q=D_{t}+D_{t-1}$

$E I=F R$ 


$$
C C_{t}=(E I)(M C)
$$

$C O C C=\operatorname{COCC}_{t}+C C_{t}$

dimana:

COQ = Cumulative Order Quantity

$D_{t} \quad=$ permintaan periode sekarang

$D_{t-1} \quad=$ permintaan periode sebelumnya

EI $=$ Excess Inventory

$F R \quad=$ Future Requirement

$C C_{t} \quad=$ This Period Carrying Cost

$M C=$ Month Carried

COCC = Cumulative Order Carrying Cost

$\mathrm{COCC}_{t}=$ Cumulative Order Carrying Cost sekarang
Tabel 18 dan Tabel 19 menunjukkan hasil MRP dengan menggunakan LTC masingmasing untuk bahan baku PB dan MDF.

Perhitungan total biaya dari metodemetode yang telah digunakan ditampilkan pada Tabel 20 dan Tabel 21. Berdasarkan Tabel 20 dan 21, maka metode lot sizing yang memberikan biaya persediaan terendah adalah metode Least Total Cost (LTC).

Tabel 16. Perhitungan Metode LTC pada Bahan Baku PB

\begin{tabular}{|c|c|c|c|c|c|c|c|c|}
\hline \multirow{2}{*}{$\begin{array}{c}\text { Future } \\
\text { Requirement }\end{array}$} & \multirow{2}{*}{ In Period } & \multirow{2}{*}{$\begin{array}{c}\text { Cumulative } \\
\text { Order Quantity }\end{array}$} & \multirow{2}{*}{$\begin{array}{c}\text { Excess } \\
\text { Inventory }\end{array}$} & \multirow{2}{*}{$\begin{array}{l}\text { Month } \\
\text { Carried }\end{array}$} & \multicolumn{4}{|c|}{ Carrying Cost } \\
\hline & & & & & & is Period & $\mathrm{CuI}$ & ative Order \\
\hline 560 & 5 & 560 & 0 & 0 & $R p$ & & $\mathrm{Rp}$ & \\
\hline 896 & 6 & 1456 & 896 & 1 & $\mathrm{Rp}$ & $943.600,00$ & $\mathrm{Rp}$ & $943.600,00$ \\
\hline 0 & 7 & 1456 & 0 & 2 & $\mathrm{Rp}$ & - & $\mathrm{Rp}$ & $943.600,00$ \\
\hline 448 & 8 & 1904 & 448 & 3 & $\mathrm{Rp}$ & $1.415 .400,00$ & $\mathrm{Rp}$ & $2.359 .000,00$ \\
\hline 448 & 9 & 2352 & 448 & 4 & $R p$ & $1.887 .200,00$ & $\mathrm{Rp}$ & $4.246 .200,00$ \\
\hline 560 & 10 & 2912 & 560 & 5 & $\mathrm{Rp}$ & $2.948 .750,00$ & $\mathrm{Rp}$ & $7.194 .950,00$ \\
\hline 448 & 11 & 448 & 448 & 0 & $\mathrm{Rp}$ & - & $\mathrm{Rp}$ & - \\
\hline 336 & 12 & 784 & 336 & 1 & $\mathrm{Rp}$ & $353.850,00$ & $\mathrm{Rp}$ & $353.850,00$ \\
\hline
\end{tabular}

Tabel 17. Perhitungan Metode LTC pada Bahan Baku MDF

\begin{tabular}{|c|c|c|c|c|c|c|c|c|}
\hline \multirow{2}{*}{$\begin{array}{c}\text { Future } \\
\text { Requirement }\end{array}$} & \multirow{2}{*}{ In Period } & \multirow{2}{*}{$\begin{array}{c}\text { Cumulative } \\
\text { Order Quantity }\end{array}$} & \multirow{2}{*}{$\begin{array}{c}\text { Excess } \\
\text { Inventory }\end{array}$} & \multirow{2}{*}{\begin{tabular}{|l|} 
Month \\
Carried
\end{tabular}} & \multicolumn{4}{|c|}{ Carrying Cost } \\
\hline & & & & & \multicolumn{2}{|c|}{ This Period } & \multicolumn{2}{|c|}{ Cumulative Order } \\
\hline 170 & 5 & 170 & 0 & 0 & $\mathrm{Rp}$ & - & $\mathrm{Rp}$ & - \\
\hline 272 & 6 & 442 & 272 & 1 & $\mathrm{Rp}$ & $190.966,67$ & $\mathrm{Rp}$ & $190.966,67$ \\
\hline 0 & 7 & 442 & 0 & 2 & $\mathrm{Rp}$ & - & $\mathrm{Rp}$ & $190.966,67$ \\
\hline 136 & 8 & 578 & 136 & 3 & $\mathrm{Rp}$ & $286.450,00$ & $\mathrm{Rp}$ & $477.416,67$ \\
\hline 136 & 9 & 714 & 136 & 4 & $\mathrm{Rp}$ & $381.933,33$ & $\mathrm{Rp}$ & $859.350,00$ \\
\hline 170 & 10 & 884 & 170 & 5 & $\mathrm{Rp}$ & $596.770,83$ & $\mathrm{Rp}$ & $1.456 .120,83$ \\
\hline 136 & 11 & 1020 & 136 & 6 & $\mathrm{Rp}$ & $572.900,00$ & $\mathrm{Rp}$ & $2.029 .020,83$ \\
\hline 102 & 12 & 1122 & 102 & 7 & $\mathrm{Rp}$ & $501.287,50$ & $\mathrm{Rp}$ & $2.530 .308,33$ \\
\hline
\end{tabular}

Tabel 18. Hasil MRP Bahan Baku PB Menggunakan LTC

\begin{tabular}{|l|c|c|c|c|c|c|c|c|c|c|c|c|}
\hline Bulan & $\mathbf{1}$ & $\mathbf{2}$ & $\mathbf{3}$ & $\mathbf{4}$ & $\mathbf{5}$ & $\mathbf{6}$ & $\mathbf{7}$ & $\mathbf{8}$ & $\mathbf{9}$ & $\mathbf{1 0}$ & $\mathbf{1 1}$ & $\mathbf{1 2}$ \\
\hline Gross Requirements & 0 & 0 & 0 & 0 & 560 & 896 & 0 & 448 & 448 & 560 & 448 & 336 \\
\hline Scheduled Receipts & & & & & & & & & & & & \\
\hline Projected On Hand & 0 & 0 & 0 & 0 & 0 & 2352 & 1456 & 1456 & 1008 & 560 & 0 & 336 \\
\hline Net Requirement & 0 & 0 & 0 & 0 & 560 & 0 & 0 & 0 & 0 & 0 & 448 & 0 \\
\hline Planned Order Receipts & & & & & 2912 & & & & & & 784 & \\
\hline Planned Order Release & & & 2912 & & & & & & 784 & & & \\
\hline
\end{tabular}


Tabel 19. Hasil MRP Bahan Baku MDF Menggunakan LTC

\begin{tabular}{|l|c|c|c|c|c|c|c|c|c|c|c|c|}
\hline Bulan & $\mathbf{1}$ & $\mathbf{2}$ & $\mathbf{3}$ & $\mathbf{4}$ & $\mathbf{5}$ & $\mathbf{6}$ & $\mathbf{7}$ & $\mathbf{8}$ & $\mathbf{9}$ & $\mathbf{1 0}$ & $\mathbf{1 1}$ & $\mathbf{1 2}$ \\
\hline Gross Requirements & 0 & 0 & 0 & 0 & 170 & 272 & 0 & 136 & 136 & 170 & 136 & 102 \\
\hline Scheduled Receipts & & & & & & & & & & & & \\
\hline Projected On Hand & 0 & 0 & 0 & 0 & 0 & 952 & 680 & 680 & 544 & 408 & 238 & 102 \\
\hline Net Requirement & 0 & 0 & 0 & 0 & 170 & 0 & 0 & 0 & 0 & 0 & 0 & 0 \\
\hline Planned Order Receipts & & & & & 1122 & & & & & & & \\
\hline Planned Order Release & & & 1122 & & & & & & & & & \\
\hline
\end{tabular}

Tabel 20. Total Biaya Persediaan Bahan Baku PB

\begin{tabular}{|c|l|c|c|c|c|c|}
\hline \multicolumn{2}{|c|}{ Ke terangan } & Jumlah & & \multicolumn{1}{c|}{ Biaya } & Total \\
\hline \multirow{2}{*}{ EOQ } & Penyimpanan & 2093 unit & $\mathrm{Rp}$ & $2.204 .190,63$ & \multirow{2}{*}{$\mathrm{Rp}$} & $34.905 .440,63$ \\
\cline { 2 - 5 } & Pemesanan & $5 \mathrm{kali}$ & $\mathrm{Rp}$ & $32.701 .250,00$ & & \\
\hline \multirow{2}{*}{ POQ } & Penyimpanan & 2240 unit & $\mathrm{Rp}$ & $2.359 .000,00$ & \multirow{2}{*}{$\mathrm{Rp}$} & $28.520 .000,00$ \\
\cline { 2 - 5 } & Pemesanan & $4 \mathrm{kali}$ & $\mathrm{Rp}$ & $26.161 .000,00$ & \\
\hline \multirow{2}{*}{ LTC } & Penyimpanan & 7168 unit & $\mathrm{Rp}$ & $7.548 .800,00$ & \multirow{2}{*}{ Rp } & $20.629 .300,00$ \\
\cline { 2 - 5 } & Pemesanan & $2 \mathrm{kali}$ & $\mathrm{Rp}$ & $13.080 .500,00$ & \\
\hline
\end{tabular}

Tabel 21. Total Biaya Persediaan Bahan Baku MDF

\begin{tabular}{|c|l|c|cc|cc|}
\hline \multicolumn{2}{|c|}{ Ke terangan } & Jumlah & \multicolumn{2}{c|}{ Biaya } & \multicolumn{1}{c|}{ Total } \\
\hline \multirow{2}{*}{ EOQ } & Penyimpanan & 2064 unit & $\mathrm{Rp}$ & $1.449 .100,00$ & \multirow{2}{*}{$\mathrm{Rp}$} & $14.529 .600,00$ \\
\cline { 2 - 5 } & Pemesanan & 2 kali & $\mathrm{Rp}$ & $13.080 .500,00$ & & \\
\hline \multirow{2}{*}{ POQ } & Penyimpanan & 1428 unit & $\mathrm{Rp}$ & $1.002 .575,00$ & \multirow{2}{*}{$\mathrm{Rp}$} & $14.083 .075,00$ \\
\cline { 2 - 5 } & Pemesanan & 2 kali & $\mathrm{Rp}$ & $13.080 .500,00$ & & \\
\hline \multirow{2}{*}{ LTC } & Penyimpanan & 3604 unit & $\mathrm{Rp}$ & $2.530 .308,33$ & \multirow{2}{*}{$\mathrm{Rp}$} & $9.070 .558,33$ \\
\cline { 2 - 4 } & Pemesanan & 1 kali & $\mathrm{Rp}$ & $6.540 .250,00$ & & \\
\hline
\end{tabular}

\section{KESIMPULAN}

Kesimpulan yang didapat dari penelitian ini adalah:

1. Metode peramalan yang tepat untuk digunakan PT Rackindo Setara Perkasa dalam memperkirakan jumlah permintaan Produk C pada periode 2016 adalah dengan menggunakan metode weighted moving average (WMA), khususnya WMA 2 yang memiliki nilai MAPE untuk tahun 2015 terendah yaitu sebesar $15,17 \%$. WMA 2 yang dilakukan dalam penelitian ini menggunakan nilai weight untuk periode -1 sebesar 0,5 dan periode 2 sebesar 0,3 serta periode -3 sebesar 0,2 .

2. Perencanaan agregat tahun 2016 yang akan dipakai PT Rackindo Setara Perkasa agar perencanaan produksinya dapat berjalan lebih efisien dari aspek material, tenaga kerja, ruang/fasilitas sehingga memberikan total biaya yang terendah maka akan disusun menggunakan bantuan software LINGO 14.0. Berdasarkan perencanaan tersebut, maka didapatkan total biaya untuk perencanaan produksi yang akan dikeluarkan oleh perusahaan adalah sebesar Rp 747.116.674,00 dengan total penghematan biaya sebesar $\mathrm{Rp}$ 134.624,00 jika dibandingkan dengan metode yang sedang digunakan oleh perusahaan sekarang.

3. Metode lot sizing yang tepat yang untuk digunakan oleh PT Rackindo Setara Perkasa guna mendapatkan total biaya perencanaan pengendalian persediaan bahan baku untuk particle board (PB) dan medium densityfibreboard (MDF) yang paling optimal adalah dengan menggunakan metode Least Total Cost (LTC). Total biaya yang dikeluarkan untuk particle board (PB) sebesar Rp 20.629.300,00 dan untuk medium density fibreboard (MDF) sebesar Rp $9.070 .558,33$.

4. Hasil perencanaan persediaan bahan baku untuk particle board $(\mathrm{PB})$ dan medium density fibreboard (MDF) pada PT Rackindo Setara Perkasa dengan 
menggunakan metode Least Total Cost (LTC) dengan rincian yaitu untuk bahan baku PB didapatkan total unit yang disimpan selama tahun 2016 sebesar 7168 unit dengan total pemesanan dilakukan sebanyak 2 kali, sedangkan bahan baku MDF didapatkan total unit yang disimpan selama tahun 2016 sebesar 3604 unit dan total pemesanan dilakukan sebanyak 1 kali.

Saran dari penelitian ini adalah:

1. Peramalan permintaan Produk C pada PT Rackindo Setara Perkasa sebaiknya menggunakan metode weighted moving average, khususnya WMA 2 yang dilakukan dalam penelitian ini.

2. Perencanaan agregat Produk C pada PT Rackindo Setara Perkasa sebaiknya menggunakan optimasi dengan bantuan software LINGO 14.0 untuk mendapatkan perencanaan yang optimal.

3. Perencanaan persedian bahan baku Produk $\mathrm{C}$, khususnya bahan baku particle board (PB) dan medium density fibreboard (MDF) pada PT Rackindo Setara Perkasa sebaiknya menggunakan metode Least Total Cost (LTC). adalah:

Saran untuk penelitian selanjutnya

1. Peramalan permintaan dilakukan untuk produk-produk PT Rackindo Setara Perkasa yang lainnya sehingga dapat membuat perencanaan produksi dan pengendalian persediaan untuk multiproduct.

2. Peramalan permintaan dikombinasikan dengan metode lainnya yang lebih kompleks atau menggunakan bantuan software yang memugkinkan untuk mendapatkan peramalan dengan hasil forecast error yang lebih rendah.

3. Menggunakan metode Lot Sizing lainnya seperti Wagner-Within Algorithm, Silver Meal Heuristic, Maximum Part-Period Gain, Groff's Method dan lain-lainnya yang mungkin dapat menghasilkan total biaya yang lebih rendah.

\section{DAFTAR PUSTAKA}

Chinguwa, S., Madanhire, I., dan Musoma, T., (2013). International Journal of Science and Research, Vol. 2 No. 2 pp. 370-383.

Lindsey, M. dan Pavur, R. (2014). "Evaluating a Bayesian Approach to Forecasting Stocking Spare Parts that Require Periodic Replenishment". Advances in Business and Management Forecasting, Vol. 10 pp. 111-128. 